\title{
humanidades
}

Revista humanidades

Julio-Diciembre, 2015 •Volumen 5, número 2 •ISSN 2215-3934 • pp. 1-27

\section{Derechos humanos, emociones y neuroética}

DOI: http://dx.doi.org/10.15517/h.v5i2.21213

\section{Álvaro Carvajal Villaplana}

Doctor, profesor Catedrático en la Escuela de Filosofía y en la Sección de Filosofía y Pensamiento de la Escuela de Estudios Generales de la Universidad de Costa Rica.

Correo electrónico: villaplana.alvaro@gmail.com

Más sobre el autor:

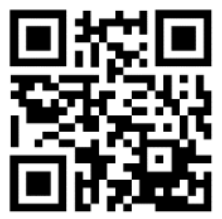

Todos los derechos reservados. Universidad de Costa Rica. Esta revista se encuentra licenciada con Creative Commons Reconocimiento-NoComercial-SinObraDerivada 3.0 Costa Rica.

Correo electrónico: humanidades.eeg@ucr.ac.cr / Sitio web: http://revistas.ucr.ac.cr/index.php/humanidades 


\section{Derechos humanos, emociones y neuroética}

\section{Resumen}

El análisis de las emociones y su relación con los derechos humanos, se sustenta de datos y argumentos científicos, en especial de la Biología, la genética y la neurociencia; de igual forma, echa mano de algunas nociones de la filosofía de la mente. Esta investigación enfatiza en los aspectos epistemológicos, se trata de una aproximación analítica que busca precisar los conceptos, marcando los límites de una manera de fundamentar los derechos humanos. Esta perspectiva busca un punto medio entre el esencialismo y la construcción social, ensaya encontrar un modelo bidereccionalidad que va del mundo de la biología al mundo de la cultura y viceversa. Aunque, se critica el enfoque de la construcción social simplista.

\section{Human rights, emotions and neuroethics}

\section{Abstract}

The analysis of emotions in their relationship to human rights draws on data and arguments of science, especially from biology, genetics and neuroscience, as well as from philosophy of mind. This research emphasizes the epistemological aspects; it is an analytical approach that seeks to define the concepts and to set the limits of a way to substantiate human rights. This perspective seeks a middle ground between essentialism and social construction and tries to find a model that will correlate the world of biology to the world of culture and viceversa. (Although, the simplistic approach to social construction is critized).

Palabras clave: Derechos humanos, emociones, neuroética, neurociencias, ética.

Keywords: Human rights, emotions, neuroethics, neurosciences, ethics. 
Este artículo se centra en un escrutinio sobre la posibilidad de una fundamentación preconceptual y prediscursiva de los derechos humanos, de acuerdo con las ciencias biológicas y neuronales ${ }^{1}$ de las emociones, por ende de los sentimientos ${ }^{2}$.

El estudio de los derechos humanos que se presenta, parte del supuesto de que los derechos humanos se dirigen al reconocimiento de la dignidad integral y concreta de los seres humanos. Dicho reconocimiento tiene una base biológica en las emociones; no obstante, también, tiene su dimensión social y cultural. En general, los aspectos biológicos del reconocimiento se activan en la interacción social; sin embargo, este asunto es más complejo, ya que los aspectos biológicos no son llanas disposiciones activadas contextualmente.

Así, los aspectos sociales y culturales no actúan o se manifiestan de manera independiente a los biológicos, sino que existe una influencia bidireccional entre ambos aspectos. Este enfoque indica que los asuntos biológicos crean condiciones que propician ciertos comportamientos, en definitiva, no existen determinismos absolutos, ya que el mismo material genético proporciona una cierta variabilidad incondicionada. Por ejemplo, la idea del ADN Móvil, que indica que existe un margen de flexibilidad en la condicionalidad genética de un $30 \%$. Asimismo, esas condiciones se manifiestan en la trama de la interacción intersubjetiva o social.

La filósofa Kathinka Evers, en su trabajo Nueroética. Cuando la materia se despierta $(2009)^{3}$, muestra, a partir de la teoría de la epigénesis neuronal, que “(...) las estructuras socioculturales y las estructuras neuronales se desarrollan en simbiosis y son causalmente pertinentes las unas a las otras (...)” (p. 17). Según esto, existe una vía de adecuación del cerebro al mundo, en la que “(...) la

\section{El dispositivo neuronal de las emociones y la moral} arquitectura de nuestros cerebros determina nuestro comportamiento social, 
nuestras disposiciones morales inclusive, lo que influye en el tipo de sociedad que creamos (...)” (p. 17). Por otro lado, existe una adecuación que va de lo social a lo biológico: “(...) las estructuras sociales influyen en el desarrollo de nuestros cerebros (...)" (p. 17). Este es el enfoque del planteamiento del problema de John McDowell, en Mind and World (1994) ${ }^{4}$. En el mismo sentido, Adela Cortina considera que tenemos unos códigos inscritos en el cerebro en razón del proceso evolutivo, dichos códigos están vinculados con las emociones. Lo anterior nos lleva a interesarnos por las personas cercanas y a desentendernos de las lejanas (2012, p. 18); sin embargo, otros autores plantean que el interés por los cercanos puede ampliarse a los más lejanos a nosotros. Aquí el problema que se presenta es si se tiene una estructura moral innata, acuñada por la evolución, que permita distinguir entre el bien y el mal.

Esta perspectiva asume una concepción dinámica de la naturaleza y de lo social, ya que las "realidades" construidas y las representaciones que se tienen del cerebro cambian incesantemente en la búsqueda de sentido. Esta idea dinámica y flexible, es una de las guías que siguen muchas discusiones en temas diversos como la homosexualidad y la intersexualidad. El debate se centra entre "lo innato" y "lo adquirido", entre la naturaleza y la cultura. Esta perspectiva teórica intenta eludir el problema del dualismo y los reduccionismos, es decir, la separación entre naturaleza y sociedad, o la reducción de lo social/cultural a lo biológico, o la reducción -a veces eliminación- de lo biológico a favor de lo social. Aunque, no cabe duda de que son los cerebros, en un contexto intersubjetivo, los que crean las estructuras sociales. 
Además, en este ensayo se asume una perspectiva evolucionista, ya que no puede explicarse la aparición de la conciencia sin su base neuronal, aun cuando no está claro cómo interactúan el cerebro y la conciencia. En este sentido, el cerebro es un ente flexible y plástico. Para Changeaux, esta plasticidad neuronal es lo que permite la capacidad para cambiar de propiedades en función de su estado de actividad (1999, p. 93). De tal manera que el cerebro es proyectivo y narrativo (p. 69). Es el resultado de una simbiosis entre lo biológico y lo socio-cultural, lo que aparece en el transcurso de la evolución.

Así las cosas, puede afirmarse que las emociones son parte esencial de la conciencia, según Evers “(...) las emociones hicieron que se despierte la materia y le permitieron producir un espíritu dinámico, flexible y abierto (...)” (p. 15). Es a partir de ellas que contamos con un cerebro y una conciencia que efectúa selecciones evaluativas emocionalmente, es decir, no somos autómatas determinados.

Siguiendo a Evers, los valores y las emociones son rasgos fundamentales del cerebro activo de manera autónoma (2009/2010, p. 115), ahí se encuentra el germen de la moralidad, por esto: “(...) sin emociones ni preferencias no podría haber ninguna moralidad; ésta presupone la capacidad para seleccionar de manera preferencial (...)" (p. 115). Así, no se trata de palmarias disposiciones innatas que se activan en contextos sociales y culturales determinados, ya que esto sería todavía una explicación simplista y mecánica; tan poco son sencillas condiciones como ya se indicó, sino que estas disposiciones están en función del desarrollo de capacidades. De tal manera que estas disposiciones, condiciones y capacidades se encuentran en unas situaciones de plasticidad, dinamismo y flexibilidad, lo que permite la existencia de diferentes sistemas normativos y morales. Se puede afirmar, de acuerdo con Evers y otros filósofos(as) de la neuroética, que existe una “(...) predisposición neurológica para desarrollar sistemas de valores complejos y variados, que nos permiten funcionar en nuestros entornos físico, social y cultural” (p. 115) ${ }^{5}$. 
En este sentido, los derechos humanos tienen sustento en este desarrollo emocional. Según Jorge Mario Rodríguez en Derechos humanos: una aproximación ética (2010), los derechos humanos tienen su soporte en una conciencia moral concreta, la que supone una naturaleza humana común (p. 16), esto coincide con lo antes expuesto. Tal naturaleza humana presume un sustrato pulsional o emotivo, es decir, preconceptual y prediscursivo. Esta tendencia se articula de diferentes maneras en distintos contextos, lo que permite el entendimiento interdiscursivo (p. 109) ${ }^{6}$. A este respecto, esta conciencia moral es previa a toda visión discursiva particular, permitiendo ver los límites de las perspectivas particulares del mundo (113). Las actuales investigaciones en neurociencias y los desarrollos teóricos de la neuroética ponen de manifiesto un replanteamiento o relanzamiento de la idea de naturaleza humana. Asimismo, el estudio del cerebro y de su estructura neuronal ponen de manifiesto la necesidad de investigar los fundamentos de una ética universal. Esta concepción corresponde con la idea de que los derechos humanos son previos a cualquier sistema legal o político.

Al respecto, Thomas Pogge (2008) afirma que los derechos humanos pueden ser considerados como valores morales que pueden ser exigidos en cualquier contexto social, cultural y político. Este enfoque de los derechos como valores morales, precisamente, como valores éticos (en tanto expectativas), tiene que complementarse con un enfoque de los derechos humanos como acciones políticas, es decir, como reclamos a una comunidad política (véase a Menke; Pollaman, 2007/2010).

Es entonces que, al parecer, habría una especie de intuición que nos indica automáticamente que es lo bueno y lo malo. Por ejemplo, ante un acto de injusticia podríamos tener una emoción o un sentimiento de indignación, sin tener una razón exacta de dónde proviene dicha impresión; del mismo modo, es posible tener emociones de simpatía por los más próximos, sin contar con un discurso que lo justifique. 
Según Ralph Adolphs (2002), las emociones son estados internos de los organismos superiores que regulan de manera flexible sus interacciones con el entorno y sus relaciones sociales (p. 137). Asimismo, comenta que las emociones tienen unas bases neuronales, en ese sentido, menciona tres categorías: (a) las respuestas fisiológicas y neuronales activadas por estímulos emocionales relevantes (cambios en el sistema nervioso autónomo); (b) el reconocimiento y evaluación del significado emocional del estímulo (el conocimiento de la emoción); y (c) la experiencia emocional provocada por el estímulo (el sentimiento, una especie de concepto de la emoción) (p. 137).

A su vez, Damasio (2003/2011) distingue cuatro niveles en los que se presenta la emoción ${ }^{7}$. Estos niveles no cubren solo el sistema límbico, sino también el prefrontal. Las emociones se mueven entre la parte más inconsciente y las secciones más conscientes del cerebro. Así, según Leroux (2002, p. 11 y 132) las emociones aparecen vinculadas a respuestas de estímulos externos y esto sirve para regular las homeostasis y la interacción del organismo con el entorno. A su vez, están vinculadas con comportamientos sociales complejos, tales como estados de culpa, los celos y la vergüenza, estos cumplen funciones similares respecto al entorno social (p. 137). Según el procesamiento de las emociones, estas son representacionales, es decir, representaciones de la homeostasis (p. 153). Se trata de una representación del medio interno (imagen de uno mismo) y una representación del medio externo (incluidos los individuos que constituyen el medio social).

Además, las respuestas emocionales complejas tienen varias consecuencias, las que a su vez evolucionan en forma compleja en el tiempo. Estas implican directamente -y modulan indirectamente- la conducta automática y planificada del organismo en todos los niveles. Así, la respuesta del estado orgánico modula el funcionamiento del cerebro de varias maneras. El cerebro percibe y representa de forma detallada estos 
cambios del organismo y del estado mental, lo que origina la experiencia consciente de las emociones o "sentimientos"; la conducta emocional del organismo puede afectar al estímulo que desencadenó la respuesta emocional y generar, por tanto, un bucle retroactivo con el entorno, cuyo objetivo es aumentar la homeostasis, la supervivencia y el bienestar del organismo (Leroux, 2002, p. 154).

Según lo anterior, se tiene que las emociones pueden clasificarse en: (a) primarias o básicas y (b) sociales. Las primeras, incluyen las emociones independientes de la cultura que pueden reconocerse a partir de expresiones faciales, como la felicidad, la sorpresa, el miedo, la ira, la repugnancia y la tristeza. Estas no necesariamente están ligadas al contexto social, aunque no cabe duda que poseen papeles en el dominio social, tiene una organización más bien innata (Leroux, 2002, p. 159).

Las segundas, incluirían el orgullo, los celos, la lástima y la vergüenza; solo se manifiestan en el contexto social, y la continuidad filogenética es mucho menor que el caso de las emociones primarias. Estas dependen de la adquisición de conocimiento en el seno de la cultura, ya que aparecen más tarde en el desarrollo del individuo que las emociones primarias (p. 159). Sin embargo, existe una disputa sobre si las respuestas emocionales son producto de un bagaje cultural que ya se arrastra por aprendizaje.

Por lo general, se argumenta que, al menos, las emociones primarias son independientes del aprendizaje, puesto que la mayoría se dan automáticamente, por ejemplo, tener miedo. Según Leroux, no se trata de saber cómo tener miedo, sino a qué tener miedo (p. 113); mientras que lo primero puede estar condicionado cultural e históricamente, lo segundo es una respuesta automática, y aunque ambos procesos pueden ayudar a especificar a qué es lo que hay que tener miedo, aun así, siempre se contará con información incompleta. 
En este artículo, se sostiene que las emociones existen, por lo que no son una simple construcción social. Según ciertos enfoques constructivistas sociales, las emociones no son el resultado de procesos biológicos generales, sino que refieren y se generan, la mayoría de las veces, siguiendo planteamientos particulares de culturas específicas (Casabuberta, 2000, p. 77). Si bien es cierto que existen algunas emociones sociales que son una construcción social, ya que no cabe duda que hay algo de aprendizaje en ellas, tal es el caso de los celos; a pesar de esto, tienen su base biológica. Este tipo de emociones son un híbrido.

Bertrand Russell indica, por ejemplo, que el deseo se encuentra en un punto medio entre los instintos y el conocimiento; sin embargo, otras emociones primarias como el miedo, están más cerca de lo biológico que de lo social. Según Casacuberta, como ya se analizó, el enfoque de la construcción social no distingue entre el proceso emocional y el disparador del proceso emocional, como muestra, hay hechos que generan en el individuo miedo, y las formas de expresión de ese miedo pueden estar mediados por los contextos culturales. Por esto, uno de los retos de la neuroética es cómo establecer la relación entre razón y emociones en la formación de los juicios morales y en la toma de decisiones, puesto que las emociones cumplen un papel indispensable en la formación de dicho juicios.

Para Evers existen varias tendencias innatas, muchas de las cuales son reconocidas por otros(a) neurocientíficos(as) y filósofos(as). Entre estas están el interés por uno mismo, el deseo de control y seguridad, la disociación con lo que se considera desagradable o amenazante y la simpatía (dirigida a los más próximos). Por su parte, Arendt y Rodríguez agregan la indignación y Glover la repugnancia. Según Rodríguez no comprendemos el dolor del otro hasta que este se nos presenta en toda su crudeza, sin importar qué tanto sabíamos de ese dolor (Rodríguez, 2010, p. 113).

\section{La lógica de la situación no se explica ante las emociones de la empatía y la indignación}


Ahora bien, Arendt afirma que no sabemos cuándo hay actos de justicia o injusticia hasta que no estamos en presencia de actos injustos o de infelicidad (Arendt, 1978/2002, p. 109). Así, de acuerdo con Rodríguez, un acto de indignación se presenta frente al sufrimiento que puede ser evitado (2010, p. 114); esta es la tesis que también sostiene Arendt. Para Glover, las víctimas relatan dolorosamente sus experiencias para que las entendamos, esto con la creencia de que si el mundo las escucha, se producirá un clamor y algo se hará al respecto (Glover, 1999, p. 3). De esa manera, frente al testimonio, los hechos o las imágenes de dolor o los actos de crueldad, a veces producen repugnancia. Esto se debe al carácter moral. Para él, la respuesta humana a estas situaciones está mediada por la simpatía (p. 24-25), ya que se trata de estructuras psicológicas, respuestas básicas que ofrecen los humanos. Este autor, plantea que esto se debe a una inclinación por mostrar respeto hacia el otro, y repugnancia por la humillación.

Estos mecanismos psicológicos funcionan como frenos a la barbarie (p. 32), y del mismo modo, la simpatía puede ampliarse a personas que no conocemos Glover (1999, p. 24-25). Además, esta puede aumentar con nuestra experiencia personal del sufrimiento (p. 24). Aunque existen mecanismos psicológicos que inhiben nuestras reacciones de repugnancia y empatía, ya que el respeto y la simpatía son "respuestas humanas" que los seres humanos no siempre tienen; por lo general, es frecuente la inhumanidad. Glover apunta que las respuestas humanas son el núcleo de la humanidad, las cuales se presentan como estructuras psicológicas profundas que hacen que se manifieste la simpatía y la crueldad (p. 24). Estas respuestas de indignación, repugnancia, respeto y empatía son estructuras emocionales cuya base es biológica y neuronal. 
Claro que existen ciertos aspectos sociológicos, como lo indican Giner y Zimbardo, que favorecen los actos de crueldad e inhumanidad. Para ambos autores esta situación sociológica tiene que ver con la lógica de la situación (o el contexto). Para Giner, se trata de situaciones de conflicto, en donde la moral tiene lugar en la interacción de tres elementos: la estructura social, las intenciones e intereses de sus miembros, las creencias y actitudes ante ellas (2012, p. 27) ${ }^{8}$. Según esto, la concepción de la moralidad es el resultado del conflicto ${ }^{9}$, el cual, a su vez, es fruto de una lógica situacional, por lo que la moral vigente depende en cada caso de la lógica propia de la situación en la que tiene lugar. Pero si esto es así, si todo es relativo a la situación, cómo podemos juzgar las morales que producen daño y mal.

Para Giner, hay pasiones como la envidia, los anhelos y la emulación que poseen una explicación sociológica; asimismo, ofrecen una explicación científica tan satisfactoria como las biológicas o las neurobiológicas (Giner, 2012,p. 21) ${ }^{10}$. Sin embargo, el que existan estas emociones sociales, no niega la existencia de emociones impulsivas. De hecho diversos autores indican que existen emociones automáticas que tienen mayores componentes sociales, por lo que este argumento no resulta suficiente para negar las emociones de base biológica. En este sentido, no cabe duda, como él mismo afirma (p. 22), que tal explicación sociológica es complementaria a los enfoques neuroéticos. Por otra parte, indica que ni la neurociencia ni la biología darán cuenta de la rebelión, es decir, de la indignación ante la injusticia. Ahora, es probable que ni la neurociencia ni la evolución ${ }^{11}$ puedan ofrecer una explicación plena sobre estos fenómenos, pero lo que indica la perspectiva neuroética es que los sentimientos y las emociones de indignación e injusticia forman parte de la estructura neuronal de la moralidad, y que sin esas estructuras, no serían posibles el desarrollo de fenómenos más complejos como la rebelión. 
Zimbardo habla de "fuerzas situacionales" que conforman la conducta de los individuos en muchos contextos. Él enfatiza en el poder del sistema, en el que operan un complejo de fuerzas poderosas que crean la Situación (2012, p. 17-18). Es claro que un sistema como el campo de exterminio, en donde las personas eligen entre males, y donde alguien tuvo que hacer algo "malo" para poder sobrevivir, las personas quedan sometidas al poder de la estructura ${ }^{12}$. No obstante, los relatos de los sobrevivientes testifican de santos (como se les llamó), que a pesar del sistema, lograron sobrevivir sin necesidad de cometer males.

Según el enfoque de Zimbardo, la concepción esencialista le atribuye a la conducta humana factores disposicionales para el mal, aunque, el enfoque que él usa (el incremental), atribuye el origen del mal a factores situacionales (p. 28). Sin embargo, Zimbardo plantea que existe una naturaleza humana, por la cual cada uno puede hacer frente al poder situacional y sistémico, ya que "(...) siempre ha habido personas que se han resistido y no han cedido a la tentación. Lo que las ha librado del mal no ha sido una bondad intrínseca de carácter mágico, sino su conocimiento, la mayoría de las veces intuitivo, de unas estrategias de resistencia mental y social (...)” (p. 21). Pero esta aseveración no parece tener relación alguna con la situación, sino con las disposiciones; es decir, en su enfoque existe una disposición natural para el bien. No somos malos naturalmente, pero sí somos buenos de manera innata. Esto actúa como otra forma de esencialismo.

A pesar de que Zimbardo sostiene que la moral de los humanos depende de las "fuerzas situacionales", a la vez reconoce un contraargumento presentado a su teoría, esto cuando indica que “(...) frente al concepto de 'banalidad del mal', frente al hecho de que la gente normal y corriente pueda cometer los más viles actos de crueldad y degradación, propongo el concepto de la 'banalidad del heroísmo' para describir a los muchos hombres y mujeres corrientes que responden con heroísmo a la llamada del deber (...)" (p. 21). No obstante, esta 
respuesta no es producto del sistema, sino de ciertos procesos psicológicos que responden a la naturaleza humana, las que pueden usarse o acceder ante el poder situacional y sistémico, se trata de procesos psicológicos profundos. Pero cuando argumenta así, habla de que “(...) lo que las ha librado del mal no ha sido una bondad intrínseca de carácter mágico, sino su conocimiento, la mayoría de las veces intuitivo, de unas estrategias de resistencia mental y social (...)” (p. 21). Así, el argumento es contradictorio y confuso.

Según él, los conceptos de bien y mal se relacionan, uno no puede entenderse sin el otro; desde un punto de vista ontológico, el bien y el mal coexisten: “(...) el mundo está lleno de bondad y maldad (...)" (Zimbardo, 2012, p. 23), pero no hay barreras fijas entre ambos y se pueden intercambiar, no hay un abismo insalvable entre el bien y el mal, puesto que desde el punto de vista incremental o gradual todos somos capaces de maldad según las circunstancias. Sin embargo, lo que diría el enfoque socio/cultural/biológico es que si bien todos somos agresivos, solo algunos son violentos; no obstante, todos podemos llegar a ser violentos, se den o no se den las circunstancias adecuadas. Desde este enfoque las circunstancias no serían efectivas si no existen las disposiciones biológicas que se activan antes las circunstancias.

Ahora bien, según David Linden (2007/2010), el cerebro no tiene un diseño perfecto, de tal manera que "(...) la textura particular de nuestros sentimientos, percepciones y actos se deriva en una amplia medida del hecho de que el cerebro no sea una máquina optimizada que resuelve problemas genéticos, sino una extraña aglomeración de soluciones ad hoc que se han ido acumulando a lo largo de millones de años de historia evolutiva (...)” (p. 17). Esta configuración del cerebro es lo que permitió la aparición de muchos rasgos humanos transcendentes y únicos. Es así como en los diferentes sectores del cerebro existen muchos impulsos homeostáticos especializados que producen ciertos efectos, relacionados con las pulsiones básicas (hambre y sed) y sociales (sexo y agresividad) (p. 29). 
La amígdala es un centro cerebral que procesa las emociones y desempeña un papel particular en relación con el miedo y la agresividad, del tal manera que enlaza información sensorial que ha sido procesada por la corteza cerebral. Además, aporta respuestas automáticas que están medidas por el hipotálamo y las estructuras del tronco del encéfalo (Linden, 2007/2010, p. 30). La corteza frontal es el sustrato de la individualidad y determina las interacciones sociales y el aspecto que tengamos de nuestro sentido moral. Esto porque los sentidos no nos ofrecen una imagen exacta del mundo exterior, sino que se trata de un " (...) bricolaje evolutivo, los sentidos han sido diseñados para detectar e incluso exagerar determinados aspectos y rasgos característicos del mundo sensorial e ignorar otros. Nuestro cerebro entonces mezcla con emoción todo este caldo sensorial para crear un único relato de la experiencia en curso, susceptible de ser interpretable.

Nuestros sentidos se dedican a seleccionar aquello que les resulta más relevante y a procesar ciertos aspectos del mundo exterior para que los tengamos en cuenta (...)" (p. 98). El cerebro, en este sentido, es narrativo.

En el contexto anterior, se cuenta con el descubrimiento de las "neuronas especulares", de manera que su existencia explica algunos enigmas humanos. Estas neuronas desarrollan la capacidad de los humanos para comprender las experiencias y las motivaciones de los demás. Al permitir comprender los actos que realizan los otros -esto en término de los propios actos- podrían ofrecer una

Neuronas especulares, contagio moral y juicio moral base biológica a la teoría de los mente (Linden, 2007/2010, p. 120).

Por un lado, Charles Darwin veía la moralidad como un producto de la evolución. Esto a pesar de que la maldad se desprende de los mecanismos de control de la agresividad, los cuales se vieron alterados por la intervención de la cultura, lo que llevó a la creación de la violencia. La maldad, según Ober y Macedo (2006/2007), incluye un tipo de egoísmo que nos lleva a tratar a los otros como simples medios. Y, para De Waal, existen razones científicas para suponer que el egoísmo (al menos a nivel genético) es un mecanismo primario de selección natural (De Waal, (2006/2007), p. 12-13). 
Por otro lado, ciertas perspectivas teóricas indican que la maldad es biológica y el ser humano es considerado naturalmente maligno. Por su parte, la bondad surge como algo externo a dicha naturaleza, esto es, algo que está fuera de ella. Esta teoría De Waal la denomina como la teoría de la capa. En contraste, De Waal considera que los seres humanos son buenos por naturaleza, lo que viene heredado por los mecanismos de la evolución. Las respuestas de la bondad son evolutivas y compartidas con otros animales, son respuestas involuntarias y psicológicas, por ejemplo, la empatía, una emoción que produce un contagio emocional (p. 15). Según esta perspectiva, para De Waal existe una continuidad entre los animales no humanos y los animales humanos.

El contra argumento que se presenta a dicha idea de De Waal es que no existe tal continuidad, ya que los animales humanos son los únicos que tienen lenguaje y razón; por tanto, son capaces de juicios morales (Korsgaard). Según Frankfurt, actuar motivado por las bases biológicas es "caprichoso", dado que para poder actuar moralmente se ha de contar con razonamiento autoconsciente (2006/2007, p. 20). Esto nos sitúa en la polémica expuesta por Russell en el dilema entre la razón y la pasión ${ }^{13}$, tal y como lo plantea De Waal (p. 39).

De acuerdo con este último autor, la moralidad es prolongación directa de los instintos sociales compartidos con los animales. Para él, existe evidencia empírica para esta afirmación, ya que desde un punto de vista psicológico, la moralidad tiene un fundamento emocional e intuitivo. Así, desde las neurociencia, los datos indican que los dilemas morales activan áreas del cerebro emocionalmente implicadas, y la observación de los primates muestran tendencias que ya han sido incorporadas a la moralidad humana (p. 47) ${ }^{14}$. 
Para él, la empatía ${ }^{15}$ se debe al desarrollo de la evolución, y las formas más avanzadas de ésta son precedidas de formas más elementales (Ober y Macebo, 2006/2007, p. 49), es decir, en las conexiones emocionales tempranas y las protoconversaciones que se producen entre a madre y el (la) niño(a) (p. 49). La empatía es un mecanismo que se ubica en el ámbito social, es de tipo cognitivo, seleccionado evolutivamente para el perfeccionamiento de respuesta hacia los estados emocionales de los otros y para responder con rapidez a los mismos (p. 53). Es un proceso rutinario involuntario, como demuestran los estudios electromiográficos, de las contracciones invisibles de los músculos faciales como respuesta a otras expresiones faciales humanas; reacciones automatizadas, que se dan, aun cuando las personas no son conscientes de lo que han visto (Dimber y otros, citado por Ober y Macebo, 2006/2007, p. 65). Es decir, son reacciones instintivas, que se dan con demasiada rapidez como para estar sometidas a un control consciente. Es de esta manera que la empatía no puede solo reducirse al contagio emocional, sino que se encuentra en diferentes niveles de desarrollo. Así, la evolución ha dado lugar a especies que siguen impulsos de reciprocidad, de tal manera que la moralidad en la especie humana surgió de forma natural (p. 80-81).

Siguiendo a este autor, la moralidad es, además, un proceso intergrupal, en tanto un conjunto de capacidades como la resolución de conflictos, la cooperación o el acto de compartir (De Waal, 2006/2007, p. 82). Sin embargo, la primera forma de lealtad es hacia uno mismo, luego la familia, y se va ampliando hacia otros grupos.

A partir de las críticas, De Waal considera que entre animales no humanos y animales humanos existen continuidades y discontinuidades, pero, en general, él no hablaría de "discontinuidades", ya que la evolución no funciona a saltos, sino que los nuevos rasgos se van aprendiendo de los antiguos, por lo cual, son modificaciones. Lo que se da, entonces, son diferencias graduales, si bien la moralidad humana va un paso adelante, esto no supone una ruptura con el pasado (2006/2007, p. 201). Según él, no nacemos con ningún sistema moral concreto en la mente, sino lo que tenemos es “(...) una agenda para el aprendizaje que nos indica qué información debemos absorber. 
Ello nos permite descubrir, comprender y en última instancia interiorizar la fábrica moral de nuestra sociedad de origen (Simon, 1990, citado por De Waal, 2006/2007, p. 207). Así, nacemos con capacidad para observar normas morales y considerar la validez de dichas normas. Tenemos un sistema flexible, que gira entre los ejes de ayudar o hacer el daño (De Waal, 2006/2007, p. 207-208). Pero, en todo caso, ningún sistema moral viable está, rara vez, desvinculado de los imperativos biológicos de supervivencia y reproducción (p. 203).

De Waal plantea tres niveles o componentes básicos de la moralidad, en una situación análoga con los niveles del desarrollo de las emociones, ya analizados. Para el nivel 1 y 2 muestra un paralelismo con los animales, no así para el tercero. Sin embargo, los niveles superiores no pueden existir sin los inferiores, porque toda la moralidad forma un continuo con la sociabilidad humana (2006/2007, p. 208).

En el primer nivel se encuentran los sentimientos morales o componentes psicológicos básicos de la moralidad: empatía, reciprocidad, retribución, la resolución de conflictos y el sentido de justicia. El segundo nivel es el de la presión social que se ejerce sobre los miembros de la comunidad para que contribuya a la consecución de los objetivos comunes. El tercer nivel es la interacción social, el diálogo interior, la abstracción y la autorreflexión; aunque, para él este nivel no se aleja tanto de las tendencias sociales de los primates (p. 208-217). El enfoque evolucionista de De Waal coincide en el enfoque de la perspectiva neuroética. Igualmente, esta perspectiva contribuye a la justificación de los derechos humanos a partir del enfoque preconceptual y prediscurivo. 
Lo último que queda por indicar es que el lenguaje discursivo cumple la función de justificar los derechos humanos. Este modelo de fundamentación de los derechos humanos se dirige o supone al reconocimiento del otro. Tal reconocimiento se basa en un sentido de naturaleza común preconceptual y prediscursiva; además de un sentido original de responsabilidad asimétrica que nos configura como seres humanos y como subjetividades morales. Este sentido preconceptual y prediscursivo es evolutivo, y para su fundamentación se asume una visión neurocientífica de la conformación de la capacidad de dicho reconocimiento. Por tanto, son disposiciones neuronales que han emergido en el proceso de evolución. Estas predisposiciones llevan a un segundo nivel: el acto reflexivo y deliberativo, el que también surge como un proceso evolutivo. Es por esta razón que no basta con la manifestación biológica, ya que es necesario el aprendizaje de la violación de los derechos humanos, es decir, se aprende del dolor y del sufrimiento, pero para ello se requiere de tal capacidad corporal biológica y neuronal. Por tal motivo, un elemento indispensable de esta predisposición es que el sentimiento de indignación implica una disposición biológica y un contexto social de injusticia en el que se pueda activar esa disposición. Este sentimiento es preconceptual es un malestar indiferenciado, ya que solo después de tenerlo es posible nombrar al mal y al daño (Arendt, 1978/2002, p. 109).

En definitiva, considerando los extremos de las perspectivas esencialista y constructivistas sociales, nos colocamos en la búsqueda de una tercera vía entre esas tendencias, y siguiendo a McDowell, podemos afirmar que el ser humano es y se hace.

\section{Conclusión: Justificación racional $\mathbf{y}$ responsabilidad asimétrica}


1. Si bien este escrutinio se basa en los datos de las ciencias, en este caso específico, sus resultados todavía son preliminares, por lo que se requiere asumir el análisis de dichos datos con cautela. Empero, es claro que ya perfilan algunos resultados robustos.

2. Por otra parte, no se puede negar que las emociones destructivas, la agresividad y la violencia, son una posible razón de la violación de los derechos humanos. Los seres humanos tienen tanto la capacidad para la destrucción como para el amor. Pero unas instituciones justas y unas situaciones cordiales favorecen el florecimiento del respeto a los derechos humanos.

3. En relación con la neuroética, existen dos tendencias en el uso del término que fueron identificadas por primera vez por Adina Roskies en 2002, en The New York Times. La primera es la ética de la neurociencia, el desarrollo de una ética para la regulación de la conducta de la investigación científica y la aplicación del conocimiento a los seres humanos; es decir, una ética aplicada. La segunda es la neurociencia de la ética, que refiere al impacto del conocimiento de las neurociencias en la comprensión de la ética. En el lenguaje coloquial se habla de las "neuronas de la agencia moral", es decir, una neurociencia de la ética. Pero podría encontrarse una variante de esta última, como lo plantean Adela Cortina (2012, p. 16) y Kathinka Evers: la neuroética, la cual consiste en el estudio de las bases cerebrales, e implica buscar en las neurociencias, el fundamento de la ética o del juicio moral o del comportamiento humano. Esto conlleva a una reconceptualización de la ética, en el que se intenta dilucidar la relación entre las neuronas y el fundamento filosófico de la obligación moral. Este es el enfoque que se asume en este artículo. 
4. El marco del problema que plantea McDowell, a la vez es compartido por Habermas en Verdad y Justificación (1999/2002) y por Arendt en La vida de la mente (1978/2002). Este problema parte de buscar un punto intermedio entre el extremo de la construcción social y el extremo del mundo de lo dado, en los términos planteados por Wilfrid Sellars en Empiricism and the Philosofphy of Mind (1956). Este problema tiene sus antecedentes filosóficos en la expresión de Kant que dice "los conceptos sin intuiciones son vacíos y las intuiciones sin conceptos son ciegos". McDowell parte de la cuestión de cómo establecer la relación entre la mente y el mundo. Para él, existe una adecuación normativa -en un modelo bidireccionalidad- entre la mente y el mundo. El mundo externo a la mente, se manifiesta como lo dado. La mente se manifiesta en su espontaneidad, sin embargo, esta no puede construir el mundo a su antojo. Respecto de esto último indica que tiene que haber un "empirismo mínimo", en el que la experiencia funciona como el tribunal del pensamiento (1996/2002, p. xii y xiv). Por otra parte, el mundo externo no está solo como algo dado, sino que en él, ya hay algo de racionalidad, en el que la mente, también, actúa sobre él (p. xvii). Por tanto, no existe la dicotomía, entre la mente y el mundo, sino que ambos conforman una misma realidad (p. vxiii).

5. El problema de establecer un "paradigma" sobre la neuroética, es que no existe un acuerdo en un enfoque, sino que existe una diversidad perspectivas, que si bien se mueven en el mismo campo de la neuroética, no se ha llegado a un acuerdo sobre su fundamento. A este respecto, Adela Cortina sistematiza varias posiciones: (a) la ética universal fundamentada en el cerebro (Gazzaniga y Mora); (b) Una estructura universal: el homo reciprocans (Hauser y Levy); (c) los valores del vínculo afectivo (Patricia Churchland); (d) las razones utilitaristas de la obligación moral y (e) una neuroética filosófica: el reconocimiento cordial (Apel y Habermas). Este último es el enfoque que adopta Cortina, ya que considera es el que tiene menos problemas de fundamentación que los anteriores (2012, p. 33). 
6. Según Marc Hauser (2006/2008), el lenguaje forma parte de este bagaje instintivo (p. 17), en donde el lenguaje aparece como órgano minuciosamente diseñado como un rasgo universal de toda mente humana, de tal modo que existe -al igual como lo plantea Chonsky- una gramática universal, la que se encuentra en el corazón de nuestra facultad lingüística, como parte de los dones innatos de la especie humana (p. 17). Además, afirma que “(...) nuestra facultad moral está equipada con una gramática moral universal, una caja de herramientas apta, proveída de normas morales propia de una cultura, lo que permite juzgar (...) si determinadas acciones son permisibles, obligatorias o están prohibidas, sin necesidad de razonar conscientemente y sin tener acceso público a los principios subyacentes" (p.17-19).

7. Los niveles de las emociones se conforman como un árbol que va de abajo arriba. Se interpretan como niveles de regulación homeostática automatizada, desde lo simple a lo complejo (2003/2011, p. 41-42). En el primer nivel, se encuentran las respuestas inmunes, los reflejos básicos y la respuesta metabólica. En el segundo ubica el comportamiento de dolor y placer. En el tercer nivel superior se tienen los instintos y las motivaciones. En el nivel superior, la emociones propiamente dichas (p. 45), aquí se incluyen las emociones en sentido estricto, desde la alegría, la pena y el miedo hasta el orgullo, la vergüenza y la simpatía. Para él, “(...) el genoma se preocupa de que todos estos dispositivos se activen al nacer, o poco después, con poca o ninguna dependencia del aprendizaje, aunque, a medida que la vida continua, éste desempeñará un papel importante a la hora de determinar cuándo se van a desplegar los dispositivos. Cuanto más compleja sea la reacción, más cierto es esto (...) (p. 45). De tal manera que, “(...) el aprendizaje puede modular la ejecución del patrón estereotipado (...) (p. 45). Los sentimientos conformarían un quinto nivel, y son otro elemento de regulación homeostática, son una expresión mental de todos los demás niveles (p. 48). Todos ellas funcionan por un principio de anidamiento (véase pág. 49). 
8. Según Giner, su tesis es una alternativa al biologicismo reduccionista “(...) mi ensayo ofrece una respuesta al problema de la naturaleza y origen de la moral que es alternativa y distinta al biologicismo (o los biologicismos) y a otras formas de reduccionismo, por refinado que este sea. Una cosa es identificar raíces genéticas, neuronales o, en general, biológicas de disposiciones morales tales como la generosidad, la benevolencia y el altruismo, y otra muy distinta asumir que toda explicación se agota en esas mismas raíces (...)” (2012, p. 21). Si bien es cierto, las razones neuroéticas y neurocientíficas no agotan la explicación del problema, pero son una elemento indispensable que toda teoría que fundamente los derechos humanos ha de contemplar.

9. A este tipo de análisis lo denomina "análisis situacional", el que es dinámico, y permite entender cómo mediante la adaptación, un principio o un valor se va transformando, a veces en su contrario (Giner, 2012, p. 27). El enfoque lo ubica en una variante de individualismo metodológico. Se trata de un enfoque analítico (p. 28).

10. La idea de que existan pasiones completamente construidas socialmente, no se pone en duda.

11. Por otra parte, ante el determinismo biológico asevera que la “(...) evolución moral de la humanidad no ha seguido por la misma senda, ni cubierto las mismas etapas en su desarrollo, la evolución no ha sido rectilínea ni seguido secuencias nítidas en estadios. Sin embargo, constatarlo no equivale a negar que no haya existido evolución moral. Es sensato negar que se puede suponer que las normas morales básicas del hombre del paleolítico se asemejaban, pero no eran del todo las mismas que las de hoy, aunque ya se hace más difícil afirmar que tales normas fundamentales no hay sido las mismas en casi todas las civilizaciones (...)” (Zimbardo, 2012, p. 389). Esta crítica es válida para un enfoque lineal y determinista de la evolución, sin embargo, no parece ser válido para el enfoque que aquí se defiende. 
12. Su explicación se basa en el experimento de la prisión Stanford, en el que en el poder sutil, pero penetrante, hace que una multitud de variables situacionales pueda imponerse a la voluntad de resistirse a esta influencia (Zimbardo, 2012, p. 19). Indica que existen una serie de mecanismos psicológicos que pueden inducir a una persona buena a obrar mal, entre ellos las desindividualización, la obediencia a la autoridad, la pasividad frente a las amenazas, la autojustificación y la racionalización, entre otros (p. 20). Sin embargo, eso no sería posible si no existen las disposiciones que nos faciliten que esos mecanismos psicológicos actúen sobre las personas. Por otra parte, se tienen el caso de situaciones en las que la gente se educa en el pacifismo y sin embargo, pueden cometer el mal, es posible ilustrar esta situación en el filme La Aldea (2004) de M. Night Shyamalan, y la novela El señor de las moscas (1954) de William Golding.

13. Carvajal, Álvaro. (2010). Ética y política en el pensamiento político de Bertrand Russell. San José: Antanaclasis.

14. Según Marc Hauser, “(...) hemos desarrollado un instinto moral, una capacidad que surge de manera natural dentro de cada niño, diseñada para generar juicios inmediatos sobre lo que está moralmente bien o mal sobre la base de una gramática inconsciente de la acción. Una parte de esta maquinaria fue diseñada por la mano ciega de la selección darwiniana millones de años antes de que apareciera nuestra especie; otras partes se añadieron o perfeccionaron a lo largo de nuestra historia evolutiva y son exclusivas de los humanos y nuestra psicología oral (...)" (2006/2008, p. 17).

15. Pinker considera que la empatía consiste en una preocupación que nos empuja a sentir el dolor de los otros y alinear sus intereses a los nuestros (2012, p. 24). 
Adolphs, Ralph. (2002). Emoción y conocimiento en el cerebro humano. En Morgado, Ignacio (2002) Emoción y conociendo. La evolución del cerebro y la inteligencia, pp. 135-164. Barcelona: Tusquets.

Arana, Juan. (2010). Nuerofilosofía. Perspectivas contemporáneas. Madrid: Thémata/Plaza y Valdés.

Arendt, Hannah (1979/2002). El espíritu del espíritu. Barcelona: Paidós.

Bermúdez de Castro, José María. (2011) La evolución del talento. Cómo nuestros orígenes determinan nuestro presente. Barcelona: Debolsillo.

Bonete, Enrique. (2010) Neuroética práctica. España: Desclée de Brouwer.

Casacuberta, David. (2000). ¿Qué es una emoción? Barcelona: Crítica.

Changeaux, Jean-Pierre; Ricouer, Paul. (1999). Lo que nos hace pensar. La naturaleza de la Regla. Barcelona: Península.

Churchland, Patricia. (1986). Neurophilosophy: Toward a Unified Science of the Mind-Brain. Cambridge, Massachusetts: The MIT Press.

Cortina, Adela (Ed.). (2012). Neurofilosofía práctica. Granada: Comares.

Cortina, Adela. (2012) Neuroética: presente y futuro, en Cortina, Adela. (Ed.), (2012). Neurofilosofía práctica, pp. 9-37. Granada: Comares.

Damasio, Antonio. (2003/2011) En busca de Spinoza. Neurobiología de la emoción y los sentimientos. Barcelona: Booket.

Evers, Kathinka. (2009/2010) Neuroética. Cuando la materia se despierta. Buenos Aires: Katz.

García, Emilio. (2001) Mente y cerebro. Madrid: Síntesis.

\section{Referencias bibliográficas}


Gazzaniga, Michael. (1998). Cuestiones de la mente. Cómo interactúan la mente y el cerebro para crear nuestra vida consciente. Barcelona: Herder.

Gazzaniga, Michael. (2006). El cerebro ético. Barcelona: Paidós.

Giménez, José Manuel; Sánchez-Migallón, Sergio. (2010). De la neurociencia a la neuroética. Narrativa científica reflexión filosófica. Navarra: Eunsa.

Giner, Salvador. (2012). El origen de la moral. Salamanca: Península.

Glover, Jonathan. (1999). Humanity: A Moral History of the Twentieth Century. London: Jonathan Cape.

Greene, Joshua. (2012) Del ‘es’ neuronal al ‘debe’ moral: ¿cuáles son las implicaciones morales de la psicologíaa moral neurocientífica?, En Cortina, Adela. (Ed.), (2012) Neurofilosofía práctica, pp. 149-158. Granada: (s.e.)

Comares, Gruen, Arno. (2006/2008). ¿Es posible un mundo sin guerras? Sobre el dolor como origen de la violencia. Barcelona: Herder.

Haidt, Jonathan. (2012) El perro emocional y su cola racional: en enfoque intuicionista social del juicio moral, En Cortina, Adela. (ed.), (2012). Neurofilosofía práctica, pp. 159-215. Granada: Comares.

Hansberg, Olbeth. (1996) La diversidad de las emociones. México D. F.: Fondo de Cultura Económica.

Hauser, Marc. (2006/2008). La mente moral. Cómo la naturaleza ha desarrollado nuestro sentido del bien y del mal. Barcelona: Paidós.

Korsgaard, Cristine. (2006/2007). La inmoralidad y la singularidad de la acción humana, en Waal, Frans de, Primates y filósofos. La evolución de la moral del simio al hombre, pp. 131-153. Barcelona. Paidós. 
Leroux, Joseph. (1996/1999). El Cerebro emocional. Barcelona: Ariel/Planeta.

Leroux, Joseph. (2002). El aprendizaje del miedo: de los sistemas a las sinapsis. En Morgado, Ignacio (2002) Emoción y conociendo. La evolución del cerebro y la inteligencia. Barcelona: Tusquets.

Linden, David. (2007/2010) El cerebro Accidental. La evolución de la mente y el origen de los sentimientos. Barcelona: Paidós.

McDowell, John. (1994). Mind and World. Estados Unidos: Harvard University Press.

Morse, Stephen. (2012) "Nueva neurociencia, viejos problemas", En Cortina, Adela. (ed.), (2012). Neurofilosofía práctica. Granada: Comares, p. 235-277.

Ober, Josiah; Macedo, Stephen. (2006/2007) “Introducción”, en Waal, Frans de. (2006/2007) Primates y filósofos. La evolución de la moral del simio al hombre. Barcelona. Paidós, p. 11-22.

Pogge, Thomas. (2008) World Poverty and Human Rights: Cosmopolitan Responsibilities and Reforms, 2nd ed. Cambridge: Polity Press.

Pinker, Steven. (2012) Los ángeles que llevamos dentro. El declive de la violencia y sus implicaciones. Barcelona: Paidós.

Rodríguez, José Mario. (2010) Derechos humanos: una aproximación ética, Guatemala: FyG.

Singer, Peter. (2006/2007) Moralidad, razón y derechos de los animales, en Waal, Frans de, Primates y filósofos. La evolución de la moral del simio al hombre. Barcelona: Paidós.

Singer, Peter. (2012) Ética e intuiciones, En Cortina, Adela. (ed.), (2012).

Neurofilosofía práctica. Granada: Comares. 
Waal, Frans de. (2006/2007) Primates y filósofos. La evolución de la moral del simio al hombre. Barcelona. Paidós.

Wriht, Roberto. (2006/2007) Los usos del antropomorfismo. En Waal, Frans de.

Primates y filósofos. La evolución de la moral del simio al hombre. Barcelona. Paidós.

Zimbardo, (2007/2008) El efecto Lucifer. El porqué de la maldad. Barcelona: Paidós.

Todos los derechos reservados. Universidad de Costa Rica. Esta revista se encuentra licenciada con Creative Commons Reconocimiento-NoComercial-SinObraDerivada 3.0 Costa Rica.

Correo electrónico: humanidades.eeg@ucr.ac.cr / Sitio web: http://revistas.ucr.ac.cr/index.php/humanidades 